\title{
Faculty reluctance to report student plagiarism: A case study
}

\author{
Authors: \\ Prof. Adèle Thomas ${ }^{1}$ \\ Affiliation: \\ ${ }^{1}$ University of \\ Johannesburg, \\ South Africa

\section{Correspondence to:} \\ Prof. Adèle Thomas, \\ Department of Industrial \\ Psychology and People \\ Management, \\ University of \\ Johannesburg, \\ PO Box 524, \\ Auckland Park 2006, \\ South Africa \\ E-mail: \\ adelet@uj.ac.za \\ DOl:
}

10.15249/11-1-148

\section{Keywords:}

academic ethics; leadership; managerialism; processes; workplace bullying

\section{Abstract}

Internationally, student plagiarism is on the rise despite measures introduced by universities to detect its occurrence and to institute actions to prevent and address this practice. One of the reasons that may contribute to this problem is the reluctance of faculty to report student plagiarism. Through the medium of a disguised South African case study, this paper advances reasons to explain this oversight. Such reasons include psychological discomfort, opportunity costs, lack of procedural clarity, administrative bureaucracy and a prevailing culture of managerialism. Recommendations are furnished to faculty alerting them to practices of which they must be aware when intending to report student plagiarism. Recommendations are also proposed to university leaders and administrators with regard to leadership support for those who report student plagiarism, the development of clear policies and procedures, the reduction of bureaucratic red tape, support to students whose first language is not English and reflection on the institutional moral context within which students study.

\section{Introduction}

The incidence of student plagiarism continues to rise (Hsiao, 2015) and, while universities have adopted measures to identify and address plagiarism, faculty remain reluctant to report such cases once they are detected (Thomas \& De Bruin, 2012). Luke and Kearins (2012:881) note the "silence and complicity" inherent in the way academic institutions treat plagiarism, leading Samier (2008) to suggest that moral passivity perpetuates the problem. Plagiarism transgresses the fundamental value of integrity of the academy (Lewis et al., 2011). Students who intentionally plagiarise have lost 
their respect for the institution and have violated a core psychological contract between themselves and the university based on the critical underpinning of authentic learning (England, 2008). The literature is replete with statements that prevail upon faculty to address student plagiarism, but relatively little has been published about the need for faculty and universities to be held accountable for not addressing this practice (Parameswaran, 2007).

While faculty may be complicit in perpetuating the problem of plagiarism by failing to detect or report instances of such practice, the reasons for not doing so are more complex when issues around institutional culture and the growing corporatisation of universities are considered. As such, universities become environments in which competitiveness and power imbalances between faculty and administrators lay the breeding ground for practices that unintentionally promote individual and departmental blame in the eyes of the 'corporate' hierarchy.

The objectives of this paper are twofold: First, to give insight into to the question: Why do faculty avoid reporting student plagiarism? Second, to highlight issues for both individual and institutional reflection when faculty consider reporting plagiarism and when leaders and administrators deliberate, within the context of the broader organisational culture, the support that should be afforded for this action. An understanding of why faculty may be reluctant to report student plagiarism is enriched through the qualitative voice, in the form of a case study, of the personal experience of a professor who did so.

\section{Literature review \\ $2.1 \quad$ Student plagiarism}

One form of academic dishonesty is plagiarism or the intentional or unintentional act of gaining personal benefit from appropriating someone else's work or ideas as one's own (Carroll, 2002). For work to be regarded as plagiarised it must be available to others, it must be derived from the prior work of someone else, the manner in which the work is presented must explicitly or implicitly imply originality, and the original author and location of the original material must be obfuscated (Clarke, 2006). The term 'plagiarism' is an all-encompassing one that includes a variety of transgressions such as poor referencing and paraphrasing, copying paragraphs or entire works, and may include recycling past work, colluding with others or purchasing material over the Internet (Evans, 2006).

Minor plagiarism, perhaps unintentional, includes the citing of a source yet omitting quotation marks for direct quotation of words as well as the citation of page numbers (Colquitt, 2012). Major plagiarism includes the unintentional or intentional lack of acknowledgment of sources (Price \& Price, 2005) or the buying or copying of entire documents without acknowledgment (Park, 2003). Under the ambit of either minor or major plagiarism, attempts at "patchwriting" (Howard, 1995:788) or "close copying" (Wager, 2014:41) where grammatical changes and synonyms are inserted into copied text 
or where the paraphrasing too closesly resembles the original text, are also considered to be plagiarism.

Internationally, plagiarism, specifically perpetrated by business students, is increasing (Simha et al., 2012), with business students being regarded as the most dishonest group amongst student groups (McCabe et al., 2006; Sutton et al., 2014; Marques, 2016). In this regard, Pfeffer (2007) notes how business schools have focused on teaching students how to make money, with a resultant devaluing of values relating to honesty, integrity and idealism. Similarly, Stewart (2010:244) proposes that business education has become "big business".

Cultural misunderstandings and language challenges, manifesting in students attempting to emulate the 'good' writing of scholars (Guo, 2011), are contributing factors to student plagiarism, with the suggestion that education, religion and culture may play a role in perceptions regarding its seriousness (Lewis et al., 2011). When students are required to formulate arguments and express thoughts in a language other than the mother tongue, plagiarism may increase (Fazel \& Kowkabi, 2013) and Duff (2010) notes that such students suffer from a lack of writer-identity and doubts about their communication skills. In developing countries such as South Africa, historical schooling systems, generally, do not equip students for academic writing at university level (Ellery, 2008). In this regard, Jabulani (2014), studying the essays of postgraduate South African students, identified problems of attribution by the students who tried to emulate the original authors.

The increase in student plagiarism can be attributed, largely, to the ease of Internet access to information (Szabo \& Underwood, 2012) with over 300 websites selling student papers or providing them free of charge (Happel \& Jennings, 2008). Eret and Ok (2014) established that reasons for student Internet plagiarism include time constraints, high workloads and difficulty of assignments.

However, as students progress through the stages of academic achievement, it is expected that they understand the nature of plagiarism, and assimilate and accept the rules relating to the attribution of authorship and ideas (Cabral-Cardosa, 2004).

Increasing awareness of the potential for plagiarism through electronic access, along with greater mindfulness of the laws that govern copyright and intellectual ownership of material, has resulted in a focus on text similarity detection mechanisms and interventions (Drinan \& Bertram-Gallant, 2008) and ways of dealing with it (Kisamore et al., 2007). Some of these processes include the institution of plagiarism policies (Gullifer \& Tyson, 2014), the signing of honour codes (Hall, 2011), class instruction about referencing and citation including information on a range of penalties for transgressions (Voelker et al., 2012), practice assignments and writing skills programmes (Löfström 2011), formative feedback through tutorial interventions (Volkov et al., 2011), assistance with study planning (Löfström \& Kupila, 2013) and active classroom discussion of academic integrity and misconduct (Baetz et al., 2011). 
Universities should educate the whole person to shape the next generation of leaders (Osiemo, 2012), with faculty playing an integral role in developing student moral literacy (Zdenek \& Schochor, 2007). Palmer and Zajonc (2010) warn about the danger of equipping students with knowledge that gives them power in the world if they have not been equipped in acquiring self-knowledge that is internalised to direct their own behaviour.

Hard et al. (2006) note the prevalence of inaction among faculty in preventing student academic misconduct or in doing anything about it once they detect it. Kelley and Bonner (2005) report, too, that faculty rarely address student academic dishonesty in a formal manner and Schmelkin et al. (2008) note the apparent lack of enthusiasm by faculty to act on this assault on academic values.

In a South African study, Thomas and de Bruin (2012) explored the barriers to faculty addressing student academic dishonesty such as plagiarism. While the majority of the sample of 450 academics acknowledged the seriousness of student academic dishonesty, a non-negligible proportion appeared not to be concerned about this problem or was ambivalent about its seriousness. Significant reasons for inaction related to the personal emotional discomfort that action precipitated, the opportunity costs associated with reporting and taking disciplinary action against perpetrators, and the lack of efficient procedures to progress action after its detection.

In another South African study, De Jager and Brown (2010) found that faculty regarded plagiarism as being serious but that there was a lack of agreement about its definition and that faculty favoured dealing with the issue themselves rather than progressing it through the university structures due to the work involved in dealing with disciplinary cases. In addition, there appeared to be inconsistency, university-wide, in the disciplinary action effected.

Similarly, studies elsewhere have found that faculty report student academic dishonesty in various and inconsistent ways (Burrus et al., 2011) and are reluctant to report plagiarism due to the difficulty in compiling evidence of proof of cheating and the amount of time required to do so (Coalter et al., 2007). Elliott et al. (2013) highlight the existence of faculty cheating in the forms of self-plagiarism, data fabrication and data manipulation, and the addition of their names or those of colleagues to publications in spite of minimal intellectual contribution. In a study of 371 articles published in 19 South African management journals in 2011, Thomas and de Bruin (2015) report that $48.5 \%$ of the articles contained similarity of $15 \%$ or more to other published works. These authors note the negative impact of such practices on the academic culture and environment within which students study.

Parameswaran (2007:263) advances that student dishonesty"is a privileged crime because blame and punishment often seek out only one criminal. Faculty who are indifferent to or aid student dishonesty are rarely indicted". Indeed, she proposes that those who permit dishonesty to occur in their classrooms are morally responsible for the cheating actions 
of students and that such unwillingness to act on the problem resides in the belief that "doing undesirable actions are worse than allowing them [to happen]" (Parameswaran, 2007:265).

While faculty should be accountable for detecting and addressing student plagiarism, there is an indication of a broader underlying institutional problem surrounding this issue. For example, in a survey of deans of 50 prominent international business schools, 95\% denied that student academic dishonesty is a serious problem in their schools (Brown et al., 2010).

\subsection{Managerialism in universities}

Lazzeretti and Tavoletti (2006) provide an insight into the denial of student dishonesty when they describe how, increasingly, universities now approximate corporate institutions, adopting ideals typical of business. In this process, values are sacrificed to a culture of results, a phenomenon commonly described as managerialism. Serrano-Velarde (2010) notes how the power has shifted in universities from that of professorial authority to one of managerial authority, with pressure placed on the generation of research and teaching outputs according to a market understanding of the measurements of efficiency and performance. In this process, dealing with issues relating to academic values, such as student plagiarism, may not be given priority as it detracts from the quest to achieve outputs as defined within a market-orientated context.

As a background to contextualising the later presentation and discussion of a case study relating to student plagiarism, background is provided on the South African educational landscape and the environment it sets for issues such as plagiarism to go unreported.

The National Plan for Higher Education was introduced to achieve both equity and efficiency in South African higher education to address the legacy of apartheid (Kotecha, 2007). This plan resulted in government pressure on universities to grant access to students, previously disadvantaged by the apartheid system (Kotecha, 2007), within the context of a generally poor economic environment (Hall \& Symes, 2005). Simultaneously, managerialism emerged and the skilling of faculty in financial acumen and human resources protocols with the "unthinking assimilation" into universities of practices from the corporate world (Habib, 2011:6).

As in the UK, the US and Australia, South Africa has witnessed a rapid rise in student numbers, but also government retreat from funding and the related pressure on universities to fund their activities themselves (Stewart, 2007). To meet this challenge, Wood (2010:227) suggests that South African universities have transformed themselves into "corporatised institutions ... and wealth-generating enterprises". Weinberg (2007) notes that, in the quest to generate income, they encourage and advance commercialisation of education, embark upon applied contract research and develop stronger links with external stakeholders who have power to influence the academic project. Market-driven ideas of competition, cost reduction and profit maximisation result in universities corporatising their organisational cultures and the work they do (Vally, 2007). 
Internationally, Ryan and Guthrie (2009) note the pressure placed on faculty and academic departments to perform in terms of measurable outcomes, along with related rewards and punishments. They alert the academic community to the growing concept in universities of the student being a "valued customer or client" (Ryan \& Guthrie, 2009:324), a view that may contribute to the erosion of academic values when tough decisions need to be taken with regard to the behaviour of such a student as in the case of plagiarism. In addition, fear of student litigation and the impact of such on institutional reputation, may also contribute to inaction when dealing with student plagiarists (Thompson, 2006). Samier (2008:3) suggests that faculty inaction in dealing with student academic dishonesty is a result of accountability being defined with reference to internal political and bureaucratic university authority "instead of higher order moral principle". The move to managerialism is far removed from the concept of what a university should be: "communities of scholars researching and teaching in collegial ways; [where] those running universities [are] academic leaders rather than managers or chief executives" (Deem, 1998:47).

In line with the above thoughts, Zabrosdska and Kveton (2013) note how an institutional culture characterised by intensified workloads, funding pressures, excessive competitiveness, and power imbalances between managers and faculty tends to create the environment in which bullying flourishes.

Bullying in academic institutions is reported to be high (Giorgi et al., 2011). It is a form of indirect workplace aggression that involves isolating the target and frustrating the target's attainment of key objectives as well as undermining his or her professional standing, authority and competence (Keashly \& Neuman, 2010). Slander or personal rumours, aimed at devaluing work, constitute workplace bullying (Hershcovis, 2011) and can include verbal abuse, systematic degradation and humiliation, professional obstruction and harassment, all directed at hurting, frustrating and ultimately defeating the target (Vickers, 2002). Bullying can include indirect acts of withholding resources needed to work effectively, thus subtly masking the true underlying bullying that accompanies these acts (Cox \& Goodman, 2005). Workplace bullies encourage others to see the target as a troublemaker and a problem (Vickers, 2002). For workplace behaviour to be regarded as bullying, the target must perceive such behaviour to be "unfair, humiliating, undermining, threatening, [and] difficult to defend against ..." (Djurkovic et al., 2008:405) and the behaviour must recur over an extended period of time (Vartia, 2001).

The literature review provided a context for understanding the dynamics operating in the case that follows.

\section{Process}

Case studies are used to advance an understanding of plagiarism and academic dishonesty in disguised form (Luke \& Kearins, 2012) or undisguised form (Lewis et al., 2011). Lewis et al. (2011) advocate case studies to be one of the most influential methodologies to explore plagiarism as an avenue of academic enquiry. Central to the case study is a 
message contained in the narrative account that is more expressive than accounts from quantitative research (Jones, 2011). Pollock and Bono (2013:629) note that scholars have two jobs - exploring answers to interesting questions and "telling the story" by, amongst other things, giving it a human face without sacrificing the important theoretical foundation upon which it is built. In this way, a deeply personal issue is explored within an unambiguous social context (Jones, 2011). Personal connection is the focus of such communication (Frank, 2000) thereby conveying a wider social story that is lodged in public concerns (Sparkes, 2002). In addition, an attempt is made to "give a voice to the world of meaning that might have been unheard" (Muncey, 2005:3) upon which readers may draw to better understand their own experiences (Babbie \& Mouton, 2009). In this regard, the narrative provided in this paper should resonate with faculty who have been or who may be required to take an ethical stance on student plagiarism. However, it is acknowledged that the experiences detailed in a case study cannot be generalised, in this instance, to other universities. The case study simply serves to highlight issues that universities may consider in similar circumstances.

Lincoln and Guba (1985) note that authenticity of qualitative study endeavours to promote fairness in representation, greater understanding of social situations and the perspectives of others, and action to change. While attempts have been made to honour these ideals, a limitation inherent in any work of this nature is that of unwitting subjectivity which, perhaps, can never entirely be avoided.

While this case is based on an experience of a professor at a South African university, identifying details of the person, others involved, and the institution itself have been disguised for ethical reasons. The case protagonist was an experienced teacher, having worked in different academic environments for some 16 years, six of which occurred at the institution on which the case is based. He consented to the experience being used for this case study. In its camouflaged form, the case encapsulates events that could occur, as a whole or in part, at many universities internationally.

The case protagonist kept records of student assignments and of all communication about this matter involving faculty, administration, students and colleagues. In addition, shortly after the onset of the process, he kept records of the issues as they arose as well as his response to and reflection on them.

\subsection{Case study}

\subsubsection{Background to the case}

Professor $X$ continues the journey of making sense of experiences that gathered momentum after the morning he encountered the work of the first of six student plagiarists in the class he taught at that time. That day he stood at the intersection of two paths, the routes of each unknown. The one would demand an effort to stay on a course where the outcome was uncertain; the other was to follow a gentle exodus with a known and safe destination. There would be no external shame in choosing to follow the latter path. He had detected plagiarism and reported it, arguably fulfilling his academic 
duty; the rest was up to the discretion of the University. Professor $X$ chose the former journey not fully appreciating the terrain that lay ahead. He was later to realise that this choice would involve encountering, first-hand, the consequences of taking a stand on student plagiarism within an environment in which he automatically expected support for addressing this offence.

The final assessment for Master's students undertaking a business degree in the course taught by Professor $\mathrm{X}$ comprised the submission of an examination-equivalent assignment. Students were aware that their work would be processed through the software similarity-detection programme, Turnitin ${ }^{\mathrm{TM}}$, and received extensive instruction on how to avoid plagiarism. In addition, it was expected that postgraduate students would, at this stage, have become acquainted with the writing norms of academia and to have an understanding of how knowledge is produced (Cabral-Cardosa, 2004). The students who plagiarised were all postgraduate students and were senior staff members in their own organisations. The plagiarism included the appropriation of the assignments of other students, the incorporation of material from published articles, the buying of parts of the assignment from an Internet site that sells customised essays, all practices that cannot be construed as constituting simple mistakes or referencing errors and could be deemed to be acts of major plagiarism (Park, 2003). Professor $X$ was not dealing here with immature students in terms of their ages, their company positions or their level of study.

Over the year preceding the plagiarism transgressions, the Faculty Ethics Committee, of which Professor $X$ was the Chair, developed a process to delineate the route to be followed should academic dishonesty be detected in the work of postgraduate students. Accordingly, when Professor X identified plagiarism in student work, he followed this process. In addition, the University plagiarism policy specifically noted that plagiarism at a postgraduate level was a Level Three offence demanding investigation at departmental, faculty and university levels. The final unanimous decision by members of the Ethics Committee (from which Professor $\mathrm{X}$ recused himself) was to recommend to the Dean of the Faculty that these cases be lodged with the Academic Integrity Unit (AIU) for disciplinary processing. So far, all had proceeded according to university policy. What subsequently ensued, however, gave meaning to the concept of the "dark side" of academia that Blase and Blase (2004:254) note to include harassment and aggression.

While the students were unhappy with the decision to take action, it soon became apparent that the course administrators and some faculty, too, were unhappy with this action, despite being involved in the deliberations along the way. Attempts were made by a senior faculty member to quiz students about the instruction received from Professor $X$; faculty were called upon to provide character references for the students, one actually appearing at the subsequent disciplinary hearings; an administrator refused to provide Professor $X$ with essential documents relating to the cases. However, it is difficult, overtly, to defend or condone student plagiarism as such. Accordingly, subtle nuances in the argument were introduced: Professor $X$ had not been compassionate enough in the way in which he had dealt with this issue; students should have been informed of 
the intended reporting of their suspected plagiarism prior to the actual reporting of such and afforded an opportunity to rectify their errors (both acts that run counter to the University examinations policy). Ultimately, he received an e-mail message from the course co-ordinator stating that he had brought the department and the programme into disrepute through the manner in which he had dealt with these offences and that this would have a serious impact on the desire of future students to enrol in the programme.

\subsubsection{The hearings and beyond}

Some four months after the reporting of the cases, the AIU convened disciplinary hearings. The Dean of the Faculty demonstrated visible support for the process by attending all the hearings. All students were expelled for a period of five years. However, after the emotional turmoil of the hearings, all went silent. These students continued to attend classes and to write examinations, having received only verbal communication about the verdicts from the AIU. Over the period commencing at the time of the first reporting of the cases to the AIU to the finalisation of this matter, Professor $\mathrm{X}$ sent or forwarded some 161 e-mail messages in connection with these cases. The content of the messages related to clarification regarding the receipt of documentary evidence, the querying of missing documents, requests for information about the time of the hearings and confirmation of venues, clarification relating to the appeal process, corrections of inaccurate information, and complaints of general tardiness in settling this matter. In total, overall administrative time involving members of the faculty administration, the Dean, and Professor $X$ in dealing with these cases approximated 200 hours of which some 140 hours related to the time of Professor $X$ alone.

Tackling these cases and simultaneously dealing with administrative officials who appeared to be tardy in finalising these matters added to personal costs in both emotion and time. Professor $X$ was working amongst many faculty who were hostile and opposed to the disciplinary action taken, with the majority blending into the background as bystanders, anxious to avoid any negative fallout by association. The collegial encouragement that he received came from outside the department from other University colleagues who, themselves, were conscious of the problem of student plagiarism.

The involvement of Professor $X$ in various senior ethics structures of the University resulted in the cases achieving a high and undeniable profile within the top structures. The plagiarism policy was subsequently refined and the disciplinary process restructured, ensuring that senior academics provide input into the determination of student punishment and that young academics are supported when they report student plagiarism. In addition, discussion was triggered at an institutional level, about strategies to educate staff and students on the issue of plagiarism so that this problem could be addressed holistically. Professor $X$ relocated to another department in the University.

\section{Insights}

While the personal consequences to Professor $\mathrm{X}$ of reporting and dealing with student plagiarism are important, of greater importance, for the purpose of this paper, is that 
of understanding the reaction by departmental faculty and administrators to this event which, in similar circumstances, could serve to deter faculty from reporting student plagiarism. Three distinct processes had operated simultaneously, each of which may afford insights into why faculty do not report student plagiarism.

In the first instance, there was an unconcealed attack from the students who plagiarised. Second, there was an unexpected lack of departmental support for an action that Professor $\mathrm{X}$ assumed would be of deep concern to those who teach the future leaders of the country. Third, linked to a lack of support, a considerable amount of administrative tardiness occurred resulting in those involved in this matter expending substantial effort on unnecessary work at the expense of engaging in legitimate academic pursuits.

The aggression and attacks from the plagiarists were overt. That they are leaders in their own organisations makes their behaviour even more alarming, particularly considering the link between student dishonesty and later dishonesty in the workplace (Laduke, 2013). Thompson (2006) notes that her student plagiarists showed no remorse but looked her in the eye, protesting their innocence; they were simply angry that their plagiarism had been detected. She further suggests that this anger often sways administrators.

However, the second and third processes noted above were unexpected and subtle, and insidiously had the potential to undermine the actions of Professor $X$ to both the students and the broader University community. They warrant greater exploration.

During the months from when the plagiarism was reported and disciplinary action was effected, it is suggested that the prevailing view in the department, although not clearly expressed, was that of denial of the problem; that to acknowledge student plagiarism was to admit some weakness in the programme to the leadership of the University. However, academic protocol does not permit such views to be overtly expressed (Samier, 2008), so the emphasis, imperceptibly, shifted from the students to the manner in which they had been treated ("it's not the issue of plagiarism that we have a problem with; it's how Professor X is dealing with it"; "we're beginning to look bad compared to other departments in the University"; "this event is singling us out"; "it looks as if we are the only department in which this happens"). Thus, the prevailing view was one of how this event and the disciplinary action that followed would appear to the University leadership, with a corporate environment model being the reference point. In this respect, faculty and departments are expected to perform in terms of results (Lazzeretti \& Tavoletti, 2006) with a drive to retain students, as customers, superseding the support afforded to a faculty member in taking action against students and their practices that erode academic values (Ryan \& Guthrie, 2009).

The first insight offered relates to the hostility experienced by Professor $\mathrm{X}$ for pursuing and reporting student plagiarism, evidenced by certain senior faculty and administrators openly siding with the perpetrators, a move that was apparent to both staff and students. The attempts to deter Professor $X$ from his action meet the criteria of workplace bullying tactics and, as such, constitute a form of workplace abuse (Giorgi et al., 2011).Vickers (2002) notes the damaging consequences of workplace bullying towards individuals, including the psychological and emotional damage that can spill over into job dissatisfaction, poor 
productivity and a decrease in psychological commitment. Djurkovic et al. (2008) suggest that experiencing such reactions from others increases the likelihood that the person will leave the organisation.

Similar to the present case, Luke and Kearins (2012) report the lack of support afforded to a professor from her own university when she reported the plagiarism of her work in a doctoral thesis, a journal article and a conference paper. She discovered that the only assistance that the University provided, in the form of legal representation and counselling in matters of plagiarism, was to students who had been accused of plagiarism.

Accordingly, the first insight relates to an appreciation of the importance of leadership support when tackling an issue of this nature as evident, in this case, through the involvement of the Dean of the Faculty and through the course of action against plagiarism that the University subsequently adopted, signalling such top leadership support. These actions served to strengthen the resolve of Professor $X$ in pursuing the cases of plagiarism to their conclusion and went some way in mitigating the psychological effects of the workplace bullying that he experienced. In his seminal work, Leading change: Why transformation efforts fail, John Kotter (1995) advocates the need to garner the backing of a powerful group when attempting any change effort, a suggestion that may well apply when tackling ethical problems at universities.

In addition to leadership support, clear, well documented and approved institutional policies and processes for dealing with student plagiarism could have circumvented much of the antagonistic behaviour of those faculty members who opposed the route taken by the Ethics Committee and Professor X. That the case resulted in a revision of the plagiarism policy and processes at the University in question indicates that existing policies and processes at the time were unclear and open to individual interpretation.

The second insight is that dealing directly with this issue demanded steadfastness and conviction in the face of denial of the primary problem by faculty and administrators and a lack of overt and covert support for dealing with it. Parameswaran (2007) suggests that faculty may intentionally deny or minimise wrongdoing by students to protect the status quo. Psychological discomfort is inevitable and is to be expected when dealing with issues of this nature. However, the events perpetuated by the denial of a serious ethical transgression compound, in great measure, this psychological discomfort.

The third insight relates to the tardy University administrative processes that hampered the timeous finalisation of the enquiries. While such processes were not directed at Professor $X$ as such, they served to compound an already fraught situation and serve as a reminder that the reporting of student transgressions should be backed up by strong administrative systems and procedures that expedite the unpleasant process.

Upon reflection of this case, it becomes easier to understand why many faculty may avoid reporting student academic dishonesty (De Jager \& Brown, 2010; Thomas \& de Bruin, 2012): the psychological cost is high to the individual and the opportunity costs at the expense of research generation, important for academic promotion, are also considerable, especially when coupled with the obfuscation in procedural clarity. 


\section{Recommendations and conclusion}

This case study endeavoured to give a voice to answering the question of why faculty resist dealing with student plagiarism, drawing out individual and institutional issues to reflect upon when faculty do decide to report student plagiarism.

The first recommendation is directed at individual faculty members who may wish to take action when they detect student plagiarism. It is essential not to assume that automatic support will be forthcoming. Accordingly, it is important to establish, at the outset, whether clear and objective processes exist to deal with student plagiarism as well as to ensure that there is senior leadership backing for the actions to be taken.

The second recommendation is directed at university administrators and leaders. It is essential that clear, consistent and comprehensive policies and procedures to address student plagiarism are institutionalised and known. Action dealing with plagiarism should not be open to individual interpretation. In addition, those who expose and report student plagiarism need to be supported. Senior leadership backing mollifies, to some extent, the psychological discomfort and personal costs inevitably associated with reporting plagiarism (Djurkovic et al., 2008). In addition, bureaucratic 'red tape' must be minimised during the course of the disciplinary process. If such support and action is present, the barriers that contribute to the avoidance of reporting student academic dishonesty, as noted by Thomas and de Bruin (2012), viz. psychological discomfort, opportunity costs at the expense of other academic work, and lack of procedural clarity, may be minimised.

The third recommendation is furnished with consideration to the fact that the South African student body comprises primarily of students whose mother tongue is not English. While at postgraduate levels it is expected that students should understand issues of plagiarism, it nevertheless is pro-active to ensure that students are able to obtain needed support if they struggle with academic literacy. This may include programmes targeted at writing skills (Löfström, 2011) as well as those focused on instilling broader academic ethics in students (Dzuranin et al., 2013; Marques, 2016).

The final recommendation is directed to the top leadership of universities. Student moral development does not exist in isolation; it is part of a chain of events within which the university, as a role model, is one important component (Williams \& Dewett, 2005). O'Connell (1998:168) notes that "our task in universities is not only to teach ethics and values for the marketplace but to model these values ourselves as we fulfil our own moral responsibility as educators in the universities where our students begin the [business] ethics journey in the first place".

If not embedded in the firm foundation of the ethos and academic culture of a university, many of the practices, often unthinkingly transferred from the corporate environment, can result in expediency when dealing with dilemmas, such as a response to detected plagiarism. Faculty and administrators may fear casting a department or programme in a poor light with the institutional hierarchy (Ryan \& Guthrie, 2009). Such behaviour may proliferate within academic environments where, increasingly, financial rewards 
are allocated for the throughput of student numbers within the required periods of time, where departments are regarded as 'stable' when no overt problems have been highlighted to 'top management' and where the attraction of student numbers to the programme is paramount (Stewart, 2007). Taking action on student plagiarism has the potential to impact these processes.

It is critical for universities to reflect on practices that may subtly erode the essence of university culture characterised by Deem's (1998:47) "communities of scholars". In this regard, further research should include reflection by universities on their institutional moral responsibility (Rossouw, 2004) and should embrace interrogating internal practices such as the ones described in this account. The development of a strong academic community promotes faculty commitment to the values that universities often espouse as being sacred - honesty, trust, fairness, respect and responsibility (Keohane, 1999) and, arguably, ones that support ethical practices within both the student body and the staff of the institution. Within this reflection, the insidious practices that have unthinkingly been incorporated from business into universities need to be identified and surfaced for discussion in the light of the obligations of universities to shape the development of future leaders (Osiemo, 2012).

This paper contributes to an understanding of why faculty may avoid dealing with the growing international problem of student plagiarism. When interrogating why faculty may avoid addressing this problem, the case illustrates that such action could incur heavy personal costs. The awareness of the personal and institutional issues raised in this paper may alert those in leadership, teaching and administrative positions at universities to factors that may be considered if student plagiarism is to be addressed.

\section{References}

Baetz, M., Zivcakova, L., Wood, E., Nosko, A., De Pasquale, D. \& Archer, K. 2011. Encouraging active classroom discussion of academic integrity and misconduct in higher education business contexts. Journal of Academic Ethics, 9(3):217-234. https://doi.org/10.1007/s10805-011-9141-4

Babbie, E. \& Mouton, J. 2009. The practice of social research. Ninth edition. Oxford: Oxford University Press.

Blase, J. \& Blase, J. 2004. The dark side of school leadership: Implications for administrator preparation. Leadership and Policy in Schools, 3(4):245-273. https://doi.org/10.1080/15700760490503733

Brown, B.S., Weible, R.J. \& Olmosk K.E. 2010. Business school deans on student academic honesty: A survey. College Student Journal, 44(2):299-308.

Burrus, R.T., Graham, J.E. \& Walker, M. 2011. Are my colleagues soft on (academic) crime? Journal of Economic and Economic Education Research, 12(3):55-64.

Cabral-Cardoso, C. 2004. Ethical misconduct in the business school: A case of plagiarism that turned bitter. Journal of Business Ethics, 49:75-89. https://doi.org/10.1023/B:BUSI.0000013864.76547.d5

Carroll, J. 2002. A handbook for deterring plagiarism in higher education. Oxford: Oxford Centre for Staff and Learning Development.

Clarke, R. 2006. Plagiarism by academics: More complex than it seems. Journal of the Association for Information Systems, 7(2):91-121.

Coalter, T., Lim, C.L. \& Wanorie, T. 2007. Factors that influence faculty actions: A study on faculty responses to academic dishonesty. International Journal for the Scholarship of Teaching and Learning, 1(1):Article 12. https://doi.org/10.20429/ijsotl.2007.010112 
Colquitt, J.A. 2012. From the editors: Plagiarism policies and screening at AMJ. Academy of Management Journal, 55(4):749-751.

Cox, E. \& Goodman, J. 2005. Belittled: The state of play on bullying. Australian University Review, 48(1):28-34.

Deem, R. 1998. 'New managerialism' and higher education: The management of performances and cultures in universities in the United Kingdom. International Studies in Sociology of Education, 8(1):47-70. https:// doi.org/10.1080/0962021980020014

De Jager, K. \& Brown, C. 2010. The tangled web: Investigating academics' views of plagiarism at the University of Cape Town. Studies in Higher Education 35(5):513-528. https://doi.org/10.1080/03075070903222641

Djurkovic, N., McCormack, D. \& Casimir, G. 2008. Workplace bullying and intention to leave: The moderating effect of perceived organisational support. Human Resource Management Journal, 18(4):405-422. https:// doi.org/10.1111/j.1748-8583.2008.00081.x

Drinan, P. \& Bertram Gallant, T. 2008. Plagiarism and academic integrity systems. Journal of Library Administration 47(3-4):125-140. https://doi.org/10.1080/01930820802186472

Duff, P.A. 2010. Language socialization into academic discourse communities. Annual Review of Applied Linguistics, 30:169-192. https://doi.org/10.1017/S0267190510000048

Dzuranin, A.C., Toppe Shortridge, R. \& Smith, P.A. 2013. Building ethical leaders: A way to integrate and assess ethics education. Journal of Business Ethics, 115:101-114. https://doi.org/10.1007/s10551-012-1371-x

Ellery, K. 2008. An investigation into electronic-source plagiarism in a first-year essay assignment. Assessment and Evaluation in Higher Education, 33(6):607-617. https://doi.org/10.1080/02602930701772788

Elliott, T.L., Marquis, L.M. \& Neal, C.S. 2013. Business ethics perspectives: Faculty plagiarism and fraud. Journal of Business Ethics, 112:91-99. https://doi.org/10.1007/s10551-012-1234-5

England, R. 2008. Plato among the plagiarists: The plagiarist as perpetrator and victim. Journal of the National Collegiate Honors Council - Online archive. http://digitalcommons.unl.edu/nchcjournals/71 [Accessed 29 May 2015].

Eret, E. \& Ok, A. 2014. Internet plagiarism in higher education: Tendencies, triggering factors and reasons among teacher candidates. Assessment and Evaluation in Higher Education, 39(8):1002-1016. https://doi.or g/10.1080/02602938.2014.880776

Evans, R. 2006. Evaluating an electronic plagiarism detection service. Active Learning in Higher Education, 7(1):87-99. https://doi.org/10.1177/1469787406061150

Fazel, I. \& Kowkabi, N. 2013. Students' source misuse in language classrooms: Sharing experiences. TESL Canada Journal, 31(1):86-95. https://doi.org/10.18806/tesl.v31i1.1168

Frank, A.W. 2000. The standpoint of storyteller. Qualitative Health Research, 10(3):354-365. https://doi. org/10.1177/104973200129118499

Giorgi, G., Arenas, A. \& Leon-Perez, J.M. 2011. An operative measure of workplace bullying: The negative acts questionnaire across Italian companies. Industrial Health, 49:686-695. https://doi.org/10.2486/indhealth. MS1287

Gullifer, J.M. \& Tyson, G.A. 2014. Who has read the policy on plagiarism? Unpacking students' understanding of plagiarism. Studies in Higher Education, 39(7):1202-1218. https://doi.org/10.1080/03075079.2013.777412

Guo, X. 2011. Understanding student plagiarism: An empirical study in accounting education. Accounting Education: An International Journal, 20(1):17-37. https://doi.org/10.1080/09639284.2010.534577

Habib, A. 2011. Managing higher education institutions in contemporary South Africa. CODESRIA Bulletin, 3/4:5-9.

Hall, M. \& Symes, A. 2005. South African higher education in the first decade of democracy: From cooperative governance to conditional autonomy. Studies in Higher Education, 30(2):199-212. https://doi. org/10.1080/03075070500043317

Hall, S.E. 2011. Is it happening? How to avoid the deleterious effects of plagiarism and cheating in your courses. Business Communication Quarterly, 74(2):179-182. https://doi.org/10.1177/1080569911404057 
Happel, S.K. \& Jennings, M.M. 2008. An economic analysis of academic dishonesty and its deterrence in higher education. Journal of Legal Studies Education, 25(2):183-214. https://doi.org/10.1111/j.17441722.2008.00051.x

Hard, S.F., Conway, J.M. \& Moran, A.C. 2006. Faculty and college student beliefs about the frequency of student academic misconduct. The Journal of Higher Education, 77:1058-1080. https://doi.org/10.1353/ jhe.2006.0048

Hershcovis, M.S. 2011. Incivility, social undermining, bullying ... oh my! A call to reconcile constructs within workplace aggression research. Journal of Organizational Behavior, 32:499-519. https://doi.org/10.1002/ job.689

Howard, R.M. 1995. Plagiarisms, academic death penalty. College English, 57(7):788-806. https://doi. org $/ 10.2307 / 378403$

Hsiao, C-H. 2015. Impact of ethical and affective variables on cheating: Comparison of undergraduate students with and without jobs. Higher Education, 69:55-77. https://doi.org/10.1007/s10734-014-9761-x

Jabulani, S. 2014. An analysis of the language of attribution in university students' academic essays. South African Journal of Education, 34(3):1-10. https://doi.org/10.15700/201409161112

Jones, R.L. 2011. Leaving. Qualitative Inquiry, 17:631-638. https://doi.org/10.1177/1077800411414004

Keashly, L. \& Neuman, J.H. 2010. Faculty experiences with bullying in higher education. Administrative Theory \& Praxis, 32(1):48-70. https://doi.org/10.2753/ATP1084-1806320103

Kelley, K.B. \& Bonner, K. 2005. Digital text, distance education and academic dishonesty: Faculty and administrator perceptions and responses. Journal of Asynchronous Learning Networks, 9(1):43-52.

Keohane, N.O. 1999. The fundamental values of academic integrity. Durham, NC: Duke University, Center for Academic Integrity.

Kisamore, J.L., Stone, T.H. \& Jawajar I.M. 2007. Academic integrity: The relationship between individual and situational factors on misconduct contemplations. Journal of Business Ethics, 75:381-394. https://doi. org/10.1007/s 10551-006-9260-9

Kotecha, P. 2007. Developing contradictions: Diversity and the future of the South African university. Journal of Higher Education in Africa, 5(1):9-16.

Kotter, J. 1995. Leading change: Why transformation efforts fail. Harvard Business Review, 73(2):59-67.

Laduke, R.D. 2013. Academic dishonesty today, unethical practices tomorrow? Journal of Professional Nursing, 29(6):402-406. https://doi.org/10.1016/j.profnurs.2012.10.009

Lazzeretti, L. \& Tavoletti, E. 2006. Governance shifts in higher education: A cross-national comparison. European Educational Research Journal, 5(1):18-37. https://doi.org/10.2304/eerj.2006.5.1.18

Lewis, B.R., Duchac, J.E. \& Beets, S.D. 2011. An academic publisher's response to plagiarism. Journal of Business Ethics, 102:489-506. https://doi.org/10.1007/s10551-011-0827-8

Lincoln, Y.S. \& Guba, E.G. 1985. Naturalistic inquiry. Newbury Park, CA: Sage Publications.

Löfström, E. 2011. Does plagiarism mean anything? Lol: Students' conceptions of writing and citing. Journal of Academic Ethics, 9(4):257-275. https://doi.org/10.1007/s10805-011-9145-0

Löfström, E. \& Kupila, P. 2013. The instructional challenges of student plagiarism. Journal of Academic Ethics, 11(3):231-242. https://doi.org/10.1007/s10805-013-9181-z

Luke, B. \& Kearins, K. 2012. Attribution of words versus attribution of responsibilities: Academic plagiarism and university practice. Organization, 19:881-889. https://doi.org/10.1177/1350508412448857

Marques, J. 2016. Shaping morally responsible leaders: Infusing civic engagement into business ethics courses. Journal of Business Ethics, 135:270-291. https://doi.org/10.1007/s10551-014-2465-4

McCabe, D.L., Butterfield, K.D. \& Treviño, L.K. 2006. Academic dishonesty in graduate business programs: Prevalence, causes, and proposed action. Academy of Management Learning \& Education, 5(3):294-305. https://doi.org/10.5465/AMLE.2006.22697018

Muncey, T. 2005. Doing autoethnography. International Journal of Qualitative Methods, 4(1):1-12. https://doi. org/10.1177/160940690500400105 
O'Connell, D.M. 1998. From universities to the marketplace: The business ethics journey. Journal of Business Ethics, 17:1617-1622. https://doi.org/10.1023/A:1006019519031

Osiemo, L.B. 2012. Developing responsible leaders: The university at the service of the person. Journal of Business Ethics, 108:131-143. https://doi.org/10.1007/s10551-011-1087-3

Palmer, P. \& Zajonc, A. 2010. The heart of higher education. San Francisco, CA: Jossey-Bass.

Parameswaran, A. 2007. Student dishonesty and faculty responsibility. Teaching in Higher Education, 12(2):263-274. https://doi.org/10.1080/13562510701192073

Park, C. 2003. In other (people's) words: Plagiarism by university students - literature and lessons. Assessment \& Evaluation in Higher Education, 28(5):471-488. https://doi.org/10.1080/02602930301677

Pfeffer, J. 2007. What's right and still wrong with business schools? BizEd, January/February:42-49.

Pollock, T.G. \& Bono, J.E. 2013. Being Scheherazade: The importance of storytelling in academic writing. Academy of Management Journal, 56:629-634. https://doi.org/10.5465/amj.2013.4003

Price, J. \& Price, R. 2005. Finding the true incidence rate of plagiarism. International Education Journal, 6(4):421-429.

Rossouw, D. 2004. Building business ethics as an academic field. Pretoria: Business Ethics Network Africa.

Ryan, S. \& Guthrie, J. 2009. Collegial entrepreneurialism: Australian graduate schools of business. Public Management Review, 11(3):317-344. https://doi.org/10.1080/14719030902798248

Samier, E. 2008. The problem of passive evil in educational administration: Moral implications of doing nothing. International Studies in Educational Administration, 36(1):2-21.

Schmelkin, L., Pedhazur, G., Kim, S., Karin, J., Pincus, H.S. \& Silva, R. 2008. A multinational scaling of college students' perceptions of academic honesty. The Journal of Higher Education, 79:587-607. https://doi. org/10.1353/jhe.0.0021

Serrano-Velarde, K. 2010. A fish out of water? Management consultants in academia. Minerva, 48(2):125-144. https://doi.org/10.1007/s11024-010-9148-9

Simha, A., Armstrong, J.P. \& Albert, J.F. 2012. Who leads and who lags? A comparison of cheating attitudes and behaviors among leadership and business students. Journal of Education for Business, 87:316-324. https:// doi.org/10.1080/08832323.2011.625998

Sparkes, A.C. 2002. Telling tales in sport and physical activity: A qualitative journey. Champaign, IL: Human Kinetics.

Stewart, D.W. 2010. The purpose of university education. The Psychologist-Manager Journal, 13:244-250. https://doi.org/10.1080/10887156.2010.522480

Stewart, P. 2007. Re-envisioning the academic profession in the shadow of corporate managerialism. Journal of Higher Education in Africa, 5(1):131-147.

Sutton, A., Taylor, D. \& Johnston, C. 2014. A model for exploring student understandings of plagiarism. Journal of Further and Higher Education, 38(1):129-146. https://doi.org/10.1080/0309877X.2012.706807

Szabo, A. \& Underwood, J. 2012. Cybercheats: Is information and communication technology fuelling academic dishonesty? Active Learning in Higher Education, 5(2):180-199. https://doi.org/10.1177/1469787404043815

Thomas, A. \& de Bruin, G.P. 2012. Student academic dishonesty: What do academics think and do, and what are the barriers to action? African Journal of Business Ethics, 6(1):13-24. https://doi.org/10.4103/18177417.104698

Thomas, A. \& de Bruin, G.P. 2015. Plagiarism in South African management journals, South African Journal of Science, 111(1/2):Art\#2014-0017.

Thompson, C.C. 2006. Unintended lessons: Plagiarism and the university. Teachers College Record, 108(12):439-449. https://doi.org/10.1111/j.1467-9620.2006.00788.x

Vally, S. 2007. Higher education in South Africa: Market mill or public good? Journal of Higher Education in Africa, 5(1):17-28. 
Vartia, M. 2001. Consequences of workplace bullying with respect to the well-being of its targets and the observers of bullying. Scandinavian Journal of Work Environment and Health, 27(1):63-69. https://doi. org/10.5271/sjweh.588

Vickers, M.H. 2002. Bullying as unacknowledged organizational evil: A researcher's story. Employee Responsibilities and Rights Journal, 13(4):205-217. https://doi.org/10.1023/A:1014975203542

Voelker, T.A., Love, L.G. \& Petina, I. 2012. Plagiarism: What don't they know? Journal of Education for Business, 87(1):36-41. https://doi.org/10.1080/08832323.2011.552536

Volkov, A., Volkov, M. \& Tedford, P. 2011. Plagiarism: Protective prevention instead of reactive punishment. e-Journal of Business Education and Scholarship of Teaching, 5(2):22-35.

Wager, E. 2014. Defining and responding to plagiarism. Learned Publishing, 27(1):33-42. https://doi. org/10.1087/20140105

Weinberg, G.S. 2007. Vying for legitimacy: Academic vs. corporate culture. Journal of Higher Education in Africa, 5(1):61-77.

Williams, S.D. \& Dewett, T. 2005. Yes, you can teach business ethics: A review and research agenda. Journal of Leadership and Organizational Studies, 12(2):109-120. https://doi.org/10.1177/107179190501200209

Wood, F. 2010. Occult innovations in higher education: Corporate magic and the mysteries of managerialism. Prometheus, 28(3):227-244. https://doi.org/10.1080/08109028.2010.518051

Zabrosdska, K. \& Kveton, P. 2013. Prevalence and forms of workplace bullying among university employees. Employee Responsibilities and Rights Journal, 25:89-108. https://doi.org/10.1007/s10672-012-9210-x

Zdenek, B. \& Schochor, D. 2007. Developing moral literacy in the classroom. Journal of Educational Administration, 45:514-531. https://doi.org/10.1108/09578230710762481 